\title{
Production of TNF- $\alpha$, nitric oxide and hydrogen peroxide by macrophages from mice with paracoccidioidomycosis that were fed a linseed oil-enriched diet
}

\author{
Sheisa Cyléia Sargi, Márcia Machado de Oliveira Dalalio, \\ Jesuí Vergílio Visentainer, Rafael Campos Bezerra, João Ângelo de Lima Perini, \\ Flávia Braidotti Stevanato, Jeane Eliete Laguila Visentainer ${ }^{+}$
}

\author{
Laboratório de Imunogenética, Departamento de Ciências Básicas da Saúde, \\ Universidade Estadual de Maringá, Av. Colombo 5790, 87020-900 Maringá, PR, Brasil
}

\begin{abstract}
Omega-3 polyunsaturated fatty acids (n-3 PUFA) can modulate the immune system and their primary effect is on macrophage function. Paracoccidioidomycosis (PCM) is an endemic systemic mycosis in Latin America that is caused by the dimorphic fungus Paracoccidioides brasiliensis (Pb). Macrophages are the main defence against this pathogen and have microbicidal activity that is dependent on interferon- $\gamma$ and tumour necrosis factor (TNF)- $\alpha$. These cytokines stimulate the synthesis of nitric oxide $(\mathrm{NO})$ and hydrogen peroxide $\left(\mathrm{H}_{2} \mathrm{O}_{2}\right)$, leading to the death of the fungus. To study the effect of n-3 PUFA on the host immune response during experimental PCM, macrophages that were obtained from animals infected with Pb18 and fed a diet enriched by linseed (LIN) oil were cultured and challenged with the fungus in vitro. The macrophage function was analysed based on the concentrations of TNF- $\alpha$, $\mathrm{NO}$ and $\mathrm{H}_{2} \mathrm{O}_{2}$. LIN oil seems to influence the production of TNF- $\alpha$ during the development of disease. A diet enriched with LIN oil influences the microbicidal activity of the macrophages by inducing the production of cytokines and metabolites such as $\mathrm{NO}$ and $\mathrm{H}_{2} \mathrm{O}_{2}$, predominantly in the chronic phase of infection.
\end{abstract}

Key words: macrophages - Paracoccidioides brasiliensis - cytokines - $n-3$ polyunsaturated fatty acids

Currently, there is great interest in studying the effect that polyunsaturated fatty acids (PUFAs) have on the immune system, especially with respect to their effect on macrophage function (Hubbard et al. 1994, Sierra et al. 2004). The primary area of interest is related to omega (n)-6 and $n-3$ PUFA, including linoleic acid (LA) and alpha LA (ALA). These fatty acids are essential and must be ingested in the diet (Harbige 2003). Once ingested, they are converted into arachidonic acid (AA), eicosapentaenoic acid (EPA) and docosahexaenoic acid (DHA). LA is found in soybean, maize, sunflower and nut oils. The primary dietary source of $n-3$ PUFA is deep cold-water fish, such as salmon, mackerel and sardines. However, linseed (LIN) is an important vegetable source of $n-3$ PUFA. LIN contains between 44.6-51.6\% ALA (Chen et al. 2006).

The main role of AA is to act as a substrate in the synthesis of eicosanoid, which plays a role in the duration and intensity of the inflammatory response (Calder 2008). AA is a precursor of prostaglandin $\mathrm{E}_{2}\left(\mathrm{PGE}_{2}\right)$ and thromboxane $\mathrm{A}_{2}$ and is metabolised by cyclooxygenase. AA is also a precursor of leukotriene (LTB)4, which is formed via a reaction catalysed by lipooxygenase. All of the products that are enzymatically derived from AA

Financial support: Immunogenetics Laboratory/UEM + Corresponding author: jelvisentainer@gmail.com

Received 16 February 2011

Accepted 1 February 2012 are important in the inflammatory immune response. $n-3$ PUFA are important because they reduce the synthesis of the downstream products of AA metabolism (Calder 2006). An increase in the consumption of ALA results in an increase in the levels of EPA and DHA cell membrane phospholipids, thus increasing the synthesis of anti-inflammatory eicosanoids such as $\mathrm{PGE}_{3}$ and LTB5. This increased synthesis of eicosanoids results in a decrease in the level of incorporation of AA (Calder 2007). It has been previously demonstrated that a diet rich in $n-3$ PUFA can modulate the immune system and can have an effect on macrophage function and the production of cytokines, such as tumour necrosis factor- $\alpha$ (TNF- $\alpha)$ and interleukin (IL)-1 (Calder 2007). Paracoccidioidomycosis (PCM) is a human systemic mycosis caused by the dimorphic fungus Paracoccidioides brasiliensis ( $\mathrm{Pb}$ ) (Ramos \& Saraiva 2008). Pb infection occurs through the inhalation of conidia, which then transform in the lungs into an infectious, pathogenic fungus (Moreira et al. 2008, Lopes et al. 2009). The clinical presentation of PCM varies from a local, benign infection to a lethal systemic infection, depending on the level of cellular immunity.

Host-fungus interactions are complex and dynamic. After the host cell is invaded, many immunological mechanisms are triggered to combat the replication of the fungus. One of the control mechanisms that has been reported in the literature is based on the function of macrophages, which are the first line of defence against fungal infection (Gonzalez et al. 2000). However, the microbicidal function of macrophages is dependent on immune activation mediated by interferon- $\gamma$ (IFN- $\gamma$ ) (Soares et al. 2001). 
IFN- $\gamma$ stimulates macrophages to produce TNF- $\alpha$ and nitric oxide (NO), the primary effectors that inhibit fungal replication. Macrophages also produce hydrogen peroxide $\left(\mathrm{H}_{2} \mathrm{O}_{2}\right)$, which is an important fungicidal agent (Souto et al. 2000).

$\mathrm{NO}$, synthesised by the oxidation of guanidine nitrogen by arginine and by induced NO synthesis (iNOS) (Nascimento et al. 2002), is vital for killing intracellular fungi. The stimulation of iNOS depends on a balance of cytokines that are involved in the immunological response, such as T helper (Th)1, IFN- $\gamma$ and TNF- $\alpha$, together with products released by the fungus. The variations observed in the immune response during PCM are dependent on the level of fungal suppression mediated by macrophages. There is little modulation of Th-1 type cytokines during the immune response to acute phase disease and Th-2 type cytokines are predominantly expressed during this phase, leading to the activation and differentiation of B lymphocytes into plasma cells and an increase in the levels of immunoglobulins, IL-4, IL-5 and IL-10. However, during chronic and disseminated PCM, there are high levels of TNF- $\alpha$, IL-1 and IL-6 and a normal level of IL-4 (Sadahiro et al. 2007, Bernard 2008, Ramos \& Saraiva 2008).

The aim of this study was to evaluate the production of TNF- $\alpha, \mathrm{NO}$ and $\mathrm{H}_{2} \mathrm{O}_{2}$ by macrophages and to determine the influence that these metabolites have on the elimination of $\mathrm{Pb}$. The influence of these metabolites on the elimination of $\mathrm{Pb}$ was determined by counting the colony-forming units (CFUs) in a culture of peritoneal macrophages that were obtained from mice that were previously infected with the fungus and were fed a diet enriched with LIN oil, which is a source of $n-3$.

\section{SUBJECTS, MATERIALS AND METHODS}

Experimental design - To evaluate the role of $n$-3 PUFA in PCM, two groups of 60 animals were intravenously inoculated with $0.1 \mathrm{~mL}$ of a fungal suspension containing $1 \times 10^{6} \mathrm{~Pb} 18$ cells. The animals were fed a diet of feed enriched with LIN oil, which is a source of $n-3$ PUFA (ILin) or with commercial feed (ICom). Two other groups of 30 uninfected animals were fed a diet of feed enriched with LIN oil (UILin) or commercial feed (UICom). At weeks 1, 2, 4, 6 and 8, peritoneal macrophages that were obtained from six animals in each group (UICom, ICom, UILin and ILin) were cultured and challenged with $\mathrm{Pb} 18$ infection in vitro. The levels of TNF- $\alpha$ and NO in the culture supernatant, the amount of $\mathrm{H}_{2} \mathrm{O}_{2}$ produced by the cultured macrophages and the recovery of viable fungi after co-culture were evaluated. Experiments were performed in duplicate. This study was approved by and conducted in accordance with the recommendations given by the Ethical Committee for Animal Research of the State University of Maringá (UEM).

Animals - Four-week-old male Swiss mice that had an average weight of $40 \mathrm{~g}$ were provided by the central animal house of the UEM. During the experiments, the animals were housed in standard cages in the Basic Health Sciences Department under standard environmental conditions, i.e., room temperature (RT) (23$24^{\circ} \mathrm{C}$ ) and a $12 \mathrm{~h}$ dark $/ 12 \mathrm{~h}$ light cycle. Food and water were available ad libitum.
Diet - The formulated diets that were used in the experiments were composed of ingredients that are commonly used in the preparation of conventional diets (Table I). Three percent LIN oil was used in the enriched (normocaloric) diet. The moisture, total lipid content and fatty acid composition of the total lipids were monitored in the freshly prepared diets (Table II).

Experimental infection - The $\mathrm{Pb} 18$ isolate was cultured as a yeast on sterile Fava Netto medium $(0.3 \%$ protease peptone, $1 \%$ peptone, $0.5 \%$ meat extract, $0.5 \%$ yeast extract, $4 \%$ dextrose, $0.5 \% \mathrm{NaCl}, 1.6 \%$ agar and distilled water q.s.p.) (Fava Netto et al. 1969) for seven days at $35^{\circ} \mathrm{C}$. This culture was used as the source of fungus for the in vivo infection and the in vitro macrophage challenge. The

TABLE I

Percentage composition of the diet enriched with linseed oil

\begin{tabular}{lc}
\hline Content & $\begin{array}{c}\text { Mass } \\
(\%)\end{array}$ \\
\hline Corn & 45 \\
Soybean & 37.4 \\
Wheat & 6.9 \\
Linseed oil & 3 \\
Phosphate dicalcium & 2.5 \\
Calcium & 0.3 \\
Salt & 0.3 \\
Premix (vitamin + mineral $)^{a}$ & 4.5 \\
\hline
\end{tabular}

$a$ : Rovimix Roche [composition: vitamin A (500,000 UI); vitamin $\mathrm{D}_{3}$ (200,000 UI); vitamin E (5 g); vitamin K3 (1 g); vitamin B1 (1.5 g); vitamin $\mathrm{B}_{2}$ (1.5 g); $\mathrm{B}_{6}(1.5 \mathrm{~g})$; $\mathrm{B}_{12}(4 \mathrm{~g})$; vitamin C (15 $\mathrm{g})$; folic acid (500 mg); pantothenic acid (4 g); BHT (17.5 g); biotin (50 mg); colin (40 mg); copper (500 mg); cobalt (10 mg); iron $(5 \mathrm{~g})$; inositol (10 g); iodine (50mg); manganese (1.5 g); nicotinamide (7 g); selenium (10 mg); zinc (5 g) and vehicle q.s.p.].

\section{TABLE II}

Average levels of lipids, moisture and fatty acid composition (percentage of relative area) of commercial feed and the diet enriched with linseed oil

\begin{tabular}{lcc}
\hline & $\begin{array}{c}\text { Commercial } \\
\text { feed }\end{array}$ & $\begin{array}{c}\text { Diet enriched with } \\
\text { linseed oil }\end{array}$ \\
\hline Total lipids (\%) & $6.95 \pm 0.71$ & $7.50 \pm 0.68$ \\
Moisture (\%) & $9.54 \pm 0.88$ & $9.80 \pm 0.95$ \\
Fatty acid (\%) & & \\
Linoleic acid & $50.22 \pm 0.56^{a}$ & $34.58 \pm 0.01^{b}$ \\
Alpha linoleic acid & $3.78 \pm 0.05^{a}$ & $26.88 \pm 0.12^{b}$
\end{tabular}

$a, b$ : means followed by different letters in the same row are significantly different according to the Tukey test at 5\% probability. Means with standard deviations analysis on four replicates. The results are expressed as percentages of relative area. 
ICom and ILin groups of animals were intravenously inoculated via the lateral caudal vein with $1 \times 10^{6}$ viable $\mathrm{Pb} 18$ cells in $0.1 \mathrm{~mL}$ of sterile phosphate buffered saline.

Peritoneal macrophage isolation and culture - The animals were sacrificed by cervical displacement under anaesthesia [5 mg/kg of Rompun ${ }^{\circledR}$ (2-(2.6-xylidine)-5.6 dihydro-4H-1.3-thiazine hydrochloride) and $50 \mathrm{mg} / \mathrm{kg}$ of Ketamine ${ }^{\circledR}$ (ketamine chloride) at a ratio of 1:1]. Subsequently, the mice were placed inside a laminar flux chamber and fixed in the decubitus position for dissection. To obtain the peritoneal washings, the abdomen was swabbed with $70 \%$ alcohol, the mid part of abdominal skin was secured using rat-tooth forceps and $3 \mathrm{~mL}$ of cold RPMI-1640 medium (Sigma Chemical, USA) supplemented with 3.2 g HEPES, 2 g sodium bicarbonate and $40 \mu \mathrm{g} / \mathrm{mL}$ gentamicin was injected into the peritoneum. Following massage, a sterile Pasteur pipette was used to collect the peritoneal washings and the washings were placed in an ice bath. After staining with crystal violet dye, the peritoneal cells were counted in a Neubauer chamber and the concentration was adjusted to 2 x $10^{7}$ mononuclear cells per millilitre. One hundred microlitres of the cellular suspension was incubated for $2 \mathrm{~h}$ in $5 \% \mathrm{CO}_{2}$ at $37^{\circ} \mathrm{C}$ in a 96 -well microculture plate. Subsequently, non-adherent cells were removed by washing and $200 \mu \mathrm{L}$ of RPMI- 1640 containing $10 \%$ foetal calf serum (FCS) (Gibco - Invitrogen) was added to the cellular mixture. The cellular suspension was then incubated for $24 \mathrm{~h}$ in $5 \% \mathrm{CO}_{2}$ at $37^{\circ} \mathrm{C}$.

Macrophage fungicide activity - Macrophages obtained from the ICom and ILin groups and from the UICom and UILin groups were challenged in vitro with a fungal suspension at a concentration of $1 \times 10^{5}$ yeast/ well (diluted in RPMI-1640 medium with 10\% FCS). A culture containing only the fungus was used as a control. After $18 \mathrm{~h}$ of incubation at $37^{\circ} \mathrm{C}$ in $5 \% \mathrm{CO}_{2}$, the culture supernatants were collected and the wells were washed four times with $250 \mu \mathrm{L}$ of sterile distilled water to lyse the macrophages and release the intracellular fungus. One hundred-microlitre aliquots of these suspensions were placed in Petri dishes and were cultured in duplicate with sterile BHI-A medium supplemented with $4 \%$ normal horse serum, 5\% growth factor (culture filtrate of different $\mathrm{Pb}$ isolates) and $1 \%$ gentamicin. The plates were incubated at $37^{\circ} \mathrm{C}$ and the number of colonies was counted after seven days. The number of CFUs was calculated as the average of the duplicate colony counts.

$T N F-\alpha$ concentration - The concentration of TNF- $\alpha$ was evaluated in the cell supernatant aliquots using an immunoenzymatic assay (ELISA) with matching antibody pairs (R\&D System, Minneapolis, USA). This assay was performed according to the manufacturer's instructions with slight modifications. Briefly, 96-well microplates (Nunc MaxiSorp, Apogent, USA) were coated with anticytokine monoclonal antibodies by incubation for $18 \mathrm{~h}$ at $4^{\circ} \mathrm{C}$. The plates were subsequently washed three times with PBS-Tween 20, followed by treatment with a solution of non-fat dry milk dissolved in PBS. The plates were then incubated for $2 \mathrm{~h}$ at $4^{\circ} \mathrm{C}$ to block non-specific binding. The plates were washed again and then the cul- ture supernatant samples were added. The plates were then incubated for $4 \mathrm{~h}$ at $4^{\circ} \mathrm{C}$. Polyclonal anti-cytokine biotinylated antibodies were used to detect reactive antibodies. Finally, the plates were incubated for $1 \mathrm{~h}$ at $4^{\circ} \mathrm{C}$ with a streptavidin-horseradish peroxidase solution diluted in PBS and bovine serum albumin (1:200). The reaction was developed by treating with the TMB Single Solution (Zymed) substrate for $40 \mathrm{~min}$ at RT. The enzymatic reaction was stopped with $50 \mu \mathrm{L}$ of $2 \mathrm{~N} \mathrm{H}_{2} \mathrm{SO}_{4}$. The ELISA results were read at $550 \mathrm{~nm}$ in a microplate reader (ASYS). The cytokine concentration was determined by comparing the results with a standard curve obtained using a recombinant murine cytokine (R\&D System, Minneapolis, USA). All analyses were performed in duplicate and the results are expressed in $\mathrm{pg} / \mathrm{mL}$.

NO concentration - The NO concentrations in the supernatants of the macrophage cultures were measured using a colorimetric assay method based on the Griess reaction as described by Nascimento et al. (2002). Briefly, $50 \mu \mathrm{L}$ of culture supernatant was incubated with Griess reagent (1\% sulphanilamide, $0.1 \%$ $\mathrm{N}-1$-naphthyl-enediamine dihydrochloride and 2.5\% $\mathrm{H}_{3} \mathrm{PO}_{4}$ ) in 96-well microplates for $10 \mathrm{~min}$ at RT. Light absorption was determined at $550 \mathrm{~nm}$ in a microplate reader (ASYS). The NO concentrations were determined by comparing the results with the standard curve generated for sodium nitrite diluted in RPMI-1640. All analyses were performed in quadruplicate and the results are expressed in $\mathrm{mM} / \mathrm{mL}$.

$\mathrm{H}_{2} \mathrm{O}_{2}$ - After the macrophages were cultured, $100 \mu \mathrm{L}$ of phenol red buffer containing peroxidase (Sigma Chemical, USA) was added to the cell supernatant of each well. The plates were incubated at $37^{\circ} \mathrm{C}$ for $1 \mathrm{~h}$ in a humidified chamber. The reaction was then stopped by the addition of $10 \mu \mathrm{L}$ of $1 \mathrm{M} \mathrm{NaOH}$. The concentration of $\mathrm{H}_{2} \mathrm{O}_{2}$ was determined based on the standard curve for $\mathrm{H}_{2} \mathrm{O}_{2}$. The absorbance at $620 \mathrm{~nm}$ was determined using a microplate reader (ASYS). All analyses were performed in quadruplicate and the results are expressed in $\mathrm{nmol} / 10^{6}$ cells.

Statistical analysis - The results were analysed using the Kruskal-Wallis non-parametric test for independent samples. Multiple comparisons were performed using the Dunn test when the differences between the medians were significant. Comparisons between groups were performed using the t-test. All statistical analyses were carried out using the SigmaStat 2.0 statistics software program. The level of significance was set to a $\mathrm{p}<0.05$.

\section{RESULTS}

$n-3$ PUFA did not influence the production of TNF- $\alpha$ in any of the four treatment groups (UICom, ICom, UILin and ILin) during the first week. However, during the second week, there was a significant decrease in the production of TNF- $\alpha$ by macrophages from infected animals in the ILin group that were challenged with $\mathrm{Pb} 18$ in vitro relative to the TNF- $\alpha$ production by macrophages from the UILin group $(\mathrm{p}=0.05)$. Also during the second week, there was a significant increase in the synthesis of TNF- $\alpha$ by macrophages from UILin group and challenged with $\mathrm{Pb} 18$ in vitro relative to the level of synthesis of TNF- $\alpha$ by 
macrophages that were obtained from the UICom group $(p=0.029)$. The production of TNF- $\alpha$ in the UILin group was significantly higher in the fourth week than the production of TNF- $\alpha$ by the UICom group $(p=0.03)$. However, there was no significant difference in the production of TNF- $\alpha$ during the sixth week. During the eighth week, the production of TNF- $\alpha$ by macrophages was significantly lower in the ICom and ILin groups than in the UICom and UILin grops $(\mathrm{p}=0.026)$ (Fig. 1).

The NO levels did not change during the first and second weeks of observation, but an increase was observed during the fourth week when the ILin and ICom groups were compared $(p=0.056)$. During the sixth week, there was no significant difference between the ILin and UILin groups. However, there was a significant decrease in the synthesis of NO in the ILin and UILin groups relative to that in the ICom group $(p=0.013)$. This difference was also observed during the eighth week, but was no longer significant (Fig. 2).

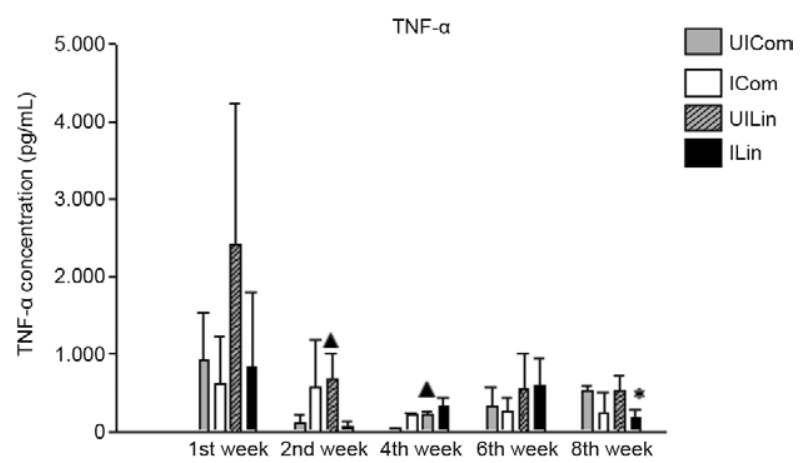

Fig. 1: tumour necrosis factor- $\alpha(\mathrm{TNF}-\alpha)$ production. ICom: group of animals that were fed a diet of commercial feed; ILin: group of animals that were fed a diet of feed enriched with linseed (LIN) oil; UICom: group of uninfected animals that were fed a diet of commercial feed; UILin: group of uninfected animals that were fed a diet enriched with LIN oil; *: $\mathrm{p}<0.05$ vs. UILin; $\boldsymbol{\Delta}: \mathrm{p}<0.05$ vs. UICom.

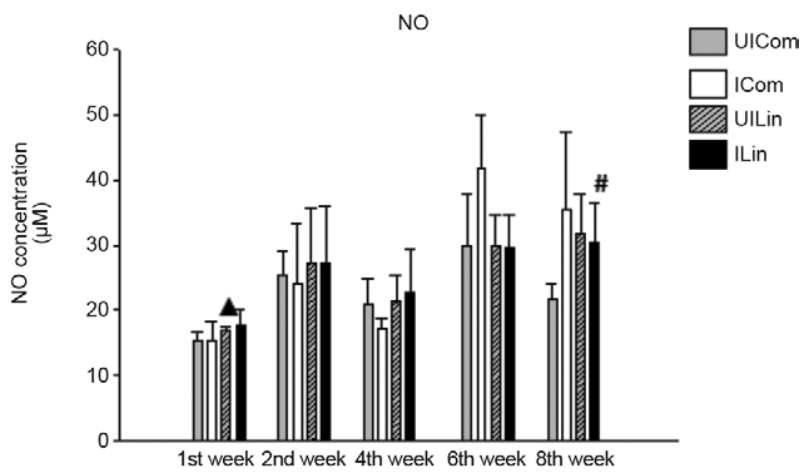

Fig. 2: nitric oxide (NO) production. ICom: group of animals that were fed a diet of commercial feed; ILin: group of animals that were fed a diet of feed enriched with linseed (LIN) oil; UICom: group of uninfected animals that were fed a diet of commercial feed; UILin: group of uninfected animals that were fed a diet enriched with LIN oil; \#: $p<0.05$ vs. ICom; $\boldsymbol{\Delta}: \mathrm{p}<0.05$ vs. UICom.
There was a significant decrease in the synthesis of $\mathrm{H}_{2} \mathrm{O}_{2}$ by macrophages obtained from the ILin and UILin groups relative to the level of $\mathrm{H}_{2} \mathrm{O}_{2}$ synthesis in the UICom and ICom groups $(p=0.018)$. This decrease was also observed when the UICom and UILin groups were compared $(p=0.001)$. However, the $\mathrm{H}_{2} \mathrm{O}_{2}$ levels were not significantly different at other time points (Fig. 3).

There was no significant difference in the number of CFUs between the groups during the first week of observation. During the second week, although not statistically significant, there was a decrease in the number of CFUs in the co-cultures of macrophages that were obtained from the UILin and ILin groups relative to number of CFUs for the UICom and ICom groups. During the fourth week, the number of CFUs for the ILin group was significantly lower than that observed for the ICom group $(p=0.049)$, but there was no significant difference between the ILin and UILin groups. During the sixth week, all groups had similar CFU levels. During the eighth week, a significant

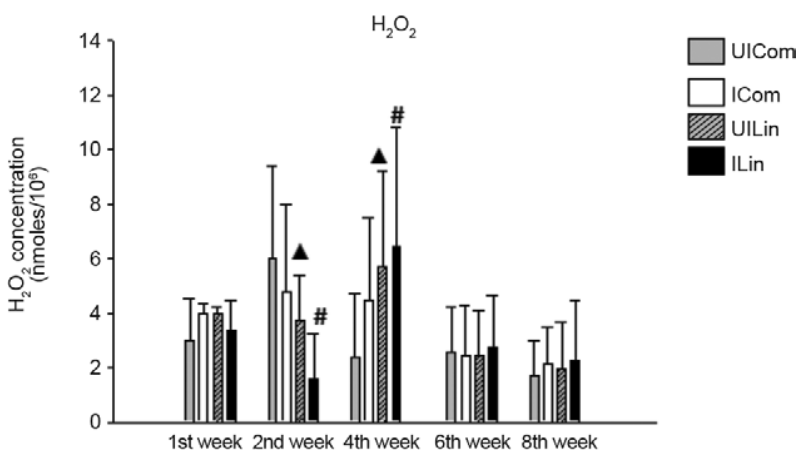

Fig. 3: hydrogen peroxide production $\left(\mathrm{H}_{2} \mathrm{O}_{2}\right)$. ICom: group of animals that were fed a diet of commercial feed; ILin: group of animals that were fed a diet of feed enriched with linseed (LIN) oil; UICom: group of uninfected animals that were fed a diet of commercial feed; UILin: group of uninfected animals that were fed a diet enriched with LIN oil; \#: $\mathrm{p}<0.05$ vs. ICom; $\boldsymbol{\Delta}: \mathrm{p}<0.05$ vs. UICom.

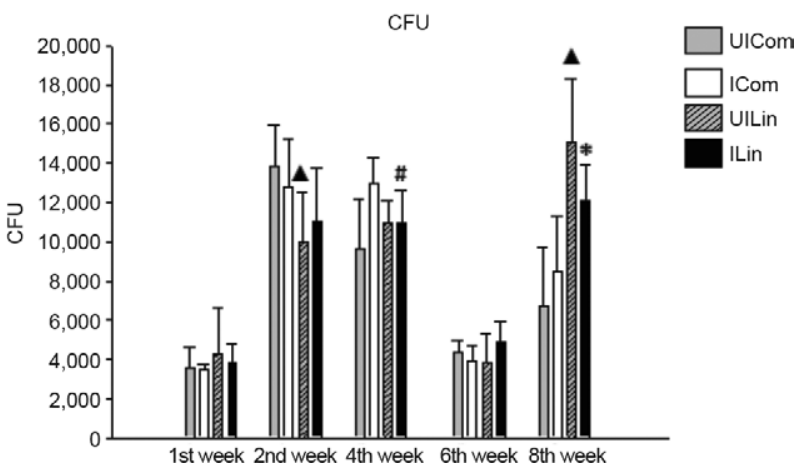

Fig. 4: colony-forming units (CFU). ICom: group of animals that were fed a diet of commercial feed; ILin: group of animals that were fed a diet of feed enriched with linseed (LIN) oil; UICom: group of uninfected animals that were fed a diet of commercial feed; UILin: group of uninfected animals that were fed a diet enriched with LIN oil; \#: $\mathrm{p}$ $<0.05$ vs. ICom; *: $p<0.05$ vs. ILin; $\boldsymbol{\Delta}: \mathrm{p}<0.05$ vs. UICom. 
increase in the number of CFUs was observed in the cocultures of macrophages from the UILin and ILin groups relative to the number of CFUs for the UICom and ICom groups $(p=0.041)$. However, when the UILin and ILin groups were compared, there was a significant decrease in the number of CFUs in the co-cultures of macrophages from the ILin group ( $p=0.02)$ (Fig. 4). In the control cultures that contained the fungus alone, a CFU count above 16,000 was observed, indicating that the culture conditions were suitable for the survival of the fungus.

\section{DISCUSSION}

This study investigated the effect of LIN oil, a source of $n$-3 PUFAs ( $\alpha$-linolenic), on macrophage function during experimental infection with $\mathrm{Pb}$. In recent years, $n-3$ PUFA has attracted a great deal of interest because they have been demonstrated to modulate the immune system, predominantly with respect to macrophage cytolytic activity during eicosanoid production and TNF- $\alpha$ synthesis (Hubbard et al. 1994).

The production of cytokines by macrophages is regulated by eicosanoids that are derived from AA. Because $n-3$ PUFA-rich diets can affect the production of these eicosanoids, it is expected that these fatty acids can directly affect cytokine production (Calder 1996, 2002).

Our results indicated that during the second week, the TNF- $\alpha$ levels were significantly lower for macrophages that were obtained from ILin group. This result suggests that $n-3$ PUFA may affect the action of macrophages in vivo, thus inhibiting their response when challenged with $\mathrm{Pb}$ in vitro. This effect seems to be associated with $\mathrm{Pb}$ infection because there was a significant difference in the production of TNF- $\alpha$ between macrophages from ICom group and macrophages from UILin group that were fed a diet that was enriched with LIN oil. Our results indicate that the level of TNF- $\alpha$ was greater in macrophages that were obtained from UICom group than in macrophages that were obtained from animals from the ICom and UILin groups. This suggested that the fungus and LIN oil may both stimulate the synthesis of TNF- $\alpha$. However, significantly lower levels of TNF- $\alpha$ were observed in the ICom and UILin groups relative to the level in the ILin group. Again, these data suggest that n-3 PUFA modulated the function of macrophages in vivo by inhibiting their response when challenged with $\mathrm{Pb}$ in culture.

It is well established that phagocytes are inhibited by inflammatory mediators such as PGE 2 . LTB4 can also stimulate both neutrophil chemotaxis and the synthesis of inflammatory cytokines by macrophages. $\mathrm{PGE}_{2}$ and LTB4 are synthesised from AA, which is an enzymatic product of $n-6$ PUFA. Enzymatically, $n-3$ PUFA are used to produce series-3 prostanoids, such as $\mathrm{PGE}_{3}$ and series-5 LTBs. These eicosanoids have a lower inflammatory potency than $\mathrm{PGE}_{2}$. $\mathrm{PGE}_{2}$ is a strong inhibitor of the synthesis of cytokines, such as IFN- $\gamma$ and TNF- $\alpha$, and $\mathrm{PGE}_{2}$ synthesis may decrease when $n-3$ PUFA are available. Stimulation by the fungus may have a greater effect, thereby increasing $\mathrm{PGE}_{2}$ levels, and could explain the significantly lower synthesis of TNF- $\alpha$ by macrophages that were obtained from ILin group relative the level of synthesis by macrophages from the UILin and ICom groups. Recovery occurs during chronic infections due to the stabilisation of the host immune response. It is known that high TNF- $\alpha$ levels are detrimental to the host and high TNF- $\alpha$ levels have been implicated in many pathological situations that, instead of favouring a response against the fungus, may impair the host defence mechanisms against a fungal pathogen.

Our results demonstrated that during the eighth week, when the chronic infection was established, the TNF- $\alpha$ level decreased along with decreases in NO synthesis. As demonstrated by the increase in the number of CFUs, these changes resulted in a lower capability of the macrophages from the ILin group to eliminate the fungus compared with macrophages from the ICom group. This result indicates that there was no relationship between infection and $n-3$ PUFA in the diet.

There are no studies that report an increase in $n-3$ PUFA levels and an increase in TNF- $\alpha$, IL-1 or IL-6 production in response to stimulation with lipopolysaccharide ex vivo. However, a substantial number of studies have observed a decrease in the production of one or more inflammatory cytokines (Sijben \& Calder 2007). In the aforementioned study, LIN oil, which contains approximately $56 \%$ ALA, was added to the diet of male volunteers. After four weeks, an increase in the incorporation of EPA by leukocytes was observed and the production of TNF- $\alpha$ and IL-1 was suppressed by approximately 30\% (Caughey et al. 1996). Thus, $n-3$ PUFA in the diet can suppress TNF- $\alpha$ and IL-1 production (James et al. 2000). The ingestion of fish oil that is rich in EPA and DHA also inhibited the production of TNF- $\alpha$ and IL-1 by murine macrophages (Calder 2007).

The mechanism responsible for the suppression of the production of these cytokines by $n-3$ PUFA is unknown, but the eicosanoid that is synthesised from AA may be involved (Sijben \& Calder 2007).

Thus, $n-3$ PUFA act by decreasing the levels of TNF- $\alpha$ and IL- 1 produced by macrophages. These data suggest that the anti-inflammatory effect of $n-3$ PUFA is mediated by the modulation of these cytokines (Wallace et al. 2001, Sierra et al. 2004, Zhang et al. 2005).

NO production by macrophages in response to stimulation with IFN- $\gamma$ and TNF- $\alpha$ is an important immune mechanism to combat fungal infection. Although the difference was not statistically significant during the fourth week, the production of these cytokines was higher in the ILin group. These levels remained high until the eighth week, suggesting that $n-3$ PUFA can interfere with the synthesis of NO because eicosanoids can regulate the enzymes that are involved in the production of NO (Pompéia et al. 2000).

In the chronic stage of infection, an increase in $\mathrm{NO}$ production suggests that the host is attempting to defend itself against the fungal infection. When the animals were fed a diet that was supplemented with LIN oil, NO synthesis was lower, but still above the baseline levels that were observed in animals in the UICom group and the NO concentration remained high until the eighth week. Thus, these data suggest that these levels may have been influenced by $n-3$ PUFA, but to a lesser extent than the effect on TNF- $\alpha$ production.

Our results indicate that there was a decrease in the synthesis of $\mathrm{H}_{2} \mathrm{O}_{2}$ in the ILin and UILin groups during 
the second week and this difference was significant during the fourth week of observation.

$\mathrm{H}_{2} \mathrm{O}_{2}$ has been suggested to not be important for the elimination of $\mathrm{Pb}$ (Bordon et al. 2007). However, this metabolite was evaluated as an indicator of the activation of peritoneal macrophages. As indicated by an increase in $\mathrm{H}_{2} \mathrm{O}_{2}, \mathrm{~Pb}$ infection, together with $n-3$ PUFA, seemed to stimulate peritoneal macrophages. It is possible that $n$-3 PUFA had an effect on the production of $\mathrm{H}_{2} \mathrm{O}_{2}$ because the enzymes involved in the secretion of $\mathrm{H}_{2} \mathrm{O}_{2}$ are influenced by $n-3$ PUFA (Pompéia et al. 2000).

These studies suggest that $n-3$ PUFA may increase the expression of iNOS in macrophages. The opposite effect has also been reported by some groups who have suggested that the iNOs transcripts and NO production by macrophages may be inhibited by some PUFA (Andrade \& Carmo 2006, Sijben \& Calder 2007). Similar results have been observed in regard to $\mathrm{H}_{2} \mathrm{O}_{2}$ production. It has previously been demonstrated that peritoneal macrophages from mice that were fed on a diet supplemented with fish oil over a period of eight weeks produced more $\mathrm{H}_{2} \mathrm{O}_{2}$ in response to stimulation by a phorbol ester than peritoneal macrophages from mice fed on a diet supplemented with coconut oil (Calder 1996).

These data suggests that lipids in the diet may affect the microbicidal activity of macrophages. Supplementation with EPA and DHA at $6 \mathrm{~g}$ /day resulted in a decrease in the production of $\mathrm{H}_{2} \mathrm{O}_{2}$ by human macrophages (Calder 2008). However, no effect on the production of reactive oxygen species by both neutrophils and monocytes was observed when a low dose of $n-3$ PUFA was used (Milles et al. 2004).

A diet supplemented with LIN oil, a source of $n-3$ fatty acid, influenced the microbicidal activity of macrophages because it interfered with the production of TNF- $\alpha$, NO and $\mathrm{H}_{2} \mathrm{O}_{2}$, especially during in the acute phase of disease. The mechanisms by which dietary fatty acids alter eicosanoids and the relationship with macrophage microbicidal activity are currently unknown, but this effect may be due to an alteration in the levels of the eicosanoid precursor, AA. New studies using $n$-3 PUFA during experimental PCM may elucidate how fatty acids can influence the survival of animals during fungal infection.

\section{ACKNOWLEDGEMENTS}

To the Laboratory of Microbiology, the Laboratory of Clinical Immunology and the Laboratory of Food Chemistry, Maringá State University.

\section{REFERENCES}

Andrade PMM, Carmo MG 2006. Ácidos graxos n-3: um link entre eicosanóides, inflamação e imunidade. Rev Mn-metabólica 8: 135-143.

Bernard G 2008. An overview of the immunopathology of the human paracoccidioidomicosys. Mycopathologia 165: 209-221.

Bordon AP, Dias-Melicio LA, Acorci MJ, Calvi SA, Peraçoli MTS, Soares AMVC 2007. Prostaglandin E2 inhibits Paracoccidioides brasiliensis killing by human monocytes. Microbes Infect 9: 744-747.

Calder PC 1996. Effects of fatty acids and dietary lipids on cells of the immune system. Proc Nutr Soc 55: 127-150.
Calder PC 2002. Dietary modification of inflammatory with lipids. Proc Nutr Soc 61: 345-358.

Calder PC 2006. $n-3$ polyunsaturated fatty acids, inflammation and inflammatory diseases. Am J Clin Nutr 83 (Suppl.): 1505S-1519S.

Calder PC 2007. Immunomodulation by omega-3 fatty acids. Prostaglandins, Leukot Essent Fatty Acids 77: 327-35.

Calder PC 2008. Polyunsaturated fatty acids, inflammatory processes and inflammatory bowel diseases. Mol Nutr Food Res 52: 885-897.

Caughey GE, Mantzioris E, Gibson RA, Cleland LG, James MJ 1996. The effect on human tumor factor $\alpha$ and interleukin 1 beta production of diets enriched in $n-3$ fatty acids from vegetables oil or fish oil. Am J Clin Nutr 63: 116-122.

Chen J, Wang L, Thompson LU 2006. Flaxseed and its components reduce metastasis after surgical excision of solid human breast tumor in nude mice. Cancer Lett 234: 168-175.

Fava Netto C, Vegas VS, Sciannamea IM, Guarnieri DB 1969. Antígeno polissacarídico do Paracoccidioides brasiliensis. Estudo do tempo de cultivo do P. brasiliensis necessário ao preparo do antígeno. Rev Inst Med Trop Sao Paulo 11: 177-181.

Gonzalez A, Gómez BL, Restrepo A, Hamilton AJ, Cano LE 2000. Nitric oxide participation in the fungicidal mechanism of gamma interferon - activated murine macrophage against Paracoccidioides brasiliensis conidia. Infect Immun 68: 2546-2552.

Harbige LS 2003. Fatty acids, the immune response and autoimmunity: a question of $n-6$ essentiality and the balance between $n-6$ and $n$-3. Lipids 38: 323-341.

Hubbard NE, Chapkin RS, Erickson KL 1994. Effect of dietary linseed oil on tumoricidal activity and eicosanoids production in murine macrophages. Lipids 29: 651-655.

James MJ, Gibson RA, Cleland LG 2000. Dietary polyunsaturated fatty acids and inflammatory mediator production. Am J Clin Nutr 71 (Suppl.): 343S-348S

Lopes DL, Araújo AS, Santos JPLS, Lyon AC, Dantas DV, Reis BS, Góes AM, Pedroso ERP 2009. Prostatic paracoccidioidomycosis: differential diagnosis of prostate cancer. Mem Inst Oswaldo Cruz 104: 33-36.

Milles EA, Banerjee T, Dooper MWBW, M'Rabet L, Graus YMF, Calder PC 2004. The influence of different combinations of $\gamma$-linolenic acid, stearidonic acid and EPA on immune function in health young male subjects. Br J Nutr 91: 893-903.

Moreira AP, Dias-Melicio LA, Peraçoli MT, Calvi SA, Soares AMVC 2008. Killing of Paracoccidioides brasiliensis yeast cells by IFN- $\gamma$ and TNF- $\alpha$ activated murine peritoneal macrophages: evidence of $\mathrm{H}_{2} \mathrm{O}_{2}$ and $\mathrm{NO}$ effector mechanisms. Mycopathologia 166: 17-23.

Nascimento FRF, Calich VLG, Rodríguez D, Russo M 2002. Dual role for nitric oxide in paracoccidioidomycosis: essential for resistance, but overproduction associated with susceptibility. J Immunol 168: 4593-4600.

Pompéia C, Lopes LR, Miyasaka CK, Procópio J, Sannomiya P, Curi R 2000. Effect of fatty acids on leukocyte function. Braz J Med Biol Res 33: 1255-1268.

Ramos ESM, Saraiva Ldo E 2008. Paracoccidioidomycosis. Dermatol Clin 26: 257-269.

Sadahiro A, Diogo CL, Oshiro TM, Shikanai-Yasuda MA 2007. Kinetics of IFN- $\gamma$, TNF- $\alpha$, IL-10 and IL-4 production by mononuclear cells stimulated with gp43 peptides in patients cured of paracoccidioidomycosis. Rev Soc Bras Med Trop 40: 156-162.

Sierra S, Lara-Villoslada F, Olivares M, Jiménez J, Boza J, Xaus J 2004. IL-10 expression is involved in the regulation of the immune response by omega 3 fatty acids. Nutri Hosp 19: 376-382. 
Sijben JWC, Calder PC 2007. Differential immunomodulation with long-chain $n$-3 PUFA in health and chronic disease. Proc Nutr Soc 66: 237-259.

Soares AMVC, Calvi SA, Peraçoli MTS, Fernandez AC, Dias LA, Dos Anjos AR 2001. Modulatory effect of prostaglandins on human monocyte activation for killing of high- and low-virulence strains of Paracoccidioides brasiliensis. Immunology 102: 480-485.

Souto JT, Figueiredo F, Furlanetto A, Pfeffer K, Rossi MA, Silva JS 2000. Interferon- $\gamma$ and tumor necrosis factor- $\alpha$ determine resist- ance to Paracoccidioides brasiliensis infection in mice. Am $J$ Pathol 156: 1811-1820.

Wallace FA, Milles EA, Evans C, Stock TE, Yaqoob P, Calder PC 2001. Dietary fatty acids influence the production of Th-1 but not Th-2 type cytokines. J Leukoc Biol 69: 449-457.

Zhang P, Smith R, Chapkin RS, McMurray DN 2005. Dietary (n-3) polyunsaturated fatty acids modulate murine Th1/Th2 balance toward the Th2 pole by suppression of Th1 development. J Nutr 135: $1745-1751$. 